\title{
A Novel Method to Assess Human Population Exposure Induced by a Wireless Cellular Network
}

\author{
Nadège Varsier, ${ }^{1,2 \star}$ David Plets, ${ }^{3}$ Yoann Corre, ${ }^{4}$ Günter Vermeeren, ${ }^{3}$ \\ Wout Joseph, ${ }^{3}$ Sam Aerts, ${ }^{3}$ Luc Martens, ${ }^{3}$ and Joe Wiart ${ }^{1,2}$ \\ ${ }^{1}$ Orange Labs, Issy Les Moulineaux, France \\ ${ }^{2}$ WHIST Lab Common Laboratory of Orange Labs and Institut Mines-Telecom, Paris, \\ France \\ ${ }^{3}$ iMinds, Wireless and Cable, Ghent University, Ghent, Belgium \\ ${ }^{4}$ Siradel, Rennes, France
}

\begin{abstract}
This paper presents a new metric to evaluate electromagnetic exposure induced by wireless cellular networks. This metric takes into account the exposure induced by base station antennas as well as exposure induced by wireless devices to evaluate average global exposure of the population in a specific geographical area. The paper first explains the concept and gives the formulation of the Exposure Index (EI). Then, the EI computation is illustrated through simple phone call scenarios (indoor office, in train) and a complete macro urban data long-term evolution scenario showing how, based on simulations, radio-planning predictions, realistic population statistics, user traffic data, and specific absorption rate calculations can be combined to assess the index. Bioelectromagnetics. 2015;9999:XX-XX. @ 2015 Wiley Periodicals, Inc.
\end{abstract}

Key words: EMF exposure; metric; uplink emitted power; downlink received power; ICT usage data

\section{INTRODUCTION}

Wireless communication systems are currently used by billions of people in almost every activity of daily life. Technological evolutions are extremely rapid, resulting in a constantly changing usage of wireless devices. New applications, extensively used on smartphones, are emerging every day resulting in an exponentially growing amount of consumed data [Cisco, 2015] and in demand of capacity to be made available by wireless networks. To support this increasing demand, we can no longer rely on traditional for macro-cellular networks only. New types of network architectures based on small cells will be needed to offload data traffic. This will result in a massive small-cell deployment in the next few years. While the access point or base station of small cells often enables user devices to transmit at lower power, it also brings access points closer to the user. Moreover, in order to carry new services, dedicated wireless systems will emerge, contributing to the increase in number of transmitter sites, especially in urban environments. As the role of wireless communications in daily life quickly expands, public concern about electromagnetic field (EMF) health risks grows just as much.
To protect the public from known health effects of EMF, limits have been established. The International Commission on Non-Ionizing Radiation Protection (ICNIRP) Guidelines [ICNIRP, 1998] defines basic restrictions that limit Specific Absorption Rate (SAR), expressed in $\mathrm{W} / \mathrm{kg}$ for radiofrequencies (RF) between $100 \mathrm{kHz}$ and $6 \mathrm{GHz}$, and are characterizing the RF human absorption. ICNIRP also define reference levels that limit incident field strength to the level inducing an exposure compliant with basic restrictions. Compliance tests, however, are based on worst-case assumptions (i.e., maximum power

Grant sponsor: European Commission in the 7th Framework Programme LEXNET; grant number: GA n 318273 .

Conflicts of interest: None.

*Correspondence to: Dr. Nadège Varsier, Orange Labs, 38-40 rue du Gènéral Leclerc, 92794 Issy les Moulineaux, France. E-mail: nadege.varsier@orange.com

Received for review 21 November 2014; Accepted 21 May 2015

DOI: $10.1002 /$ bem. 21928

Published online XX Month Year in Wiley Online Library (wileyonlinelibrary.com). 
emitted) and do not represent day-to-day exposure of the population.

The European Union has specifically addressed the need for low-EMF technologies in its Seventh Framework Program (FP7, ICT Call 8) [EU FP7 Program, 2014], by designating low-EMF system designs as a target outcome. This target outcome specifies a clear need for new network topologies and management that reduce EMF levels without compromising the user's Quality of Service (QoS). In response to this need, the FP7 LEXNET (Low EMF Exposure Future Networks) project was launched [Tesanovic et al., 2014].

Three types of RF-EMF exposure metrics are currently used: rate of RF energy absorption in human body in terms of SAR; incident electric field strength or incident power density (in the far-field of antennas); and dose, which takes into account exposure time by multiplying it with SAR [Aerts et al., 2013; Lauer et al., 2013; Plets et al., 2014].

Compliance assessment assumes worst-case exposure conditions. Compliance of personal devices (near-field exposure) and base station antennas (far-field exposure) must be evaluated separately. However, in case of realistic exposure assessment, exposure induced by near-field and far-field sources cannot be considered separately. Moreover, Gati et al. [2010] showed that realistic exposure induced by personal devices correlates strongly with exposure induced by base station antennas for certain Radio Access Technologies (RATs). The dose [Aerts et al., 2013; Lauer et al., 2013; Plets et al., 2014] combines exposure induced by near-field and far-field sources and takes exposure time into account.

A large majority of the population is using wireless devices, with $100 \%$ of some age groups owning a wireless personal device [Bigot et al., 2013], and it is very important not to decorrelate exposure to wireless devices from exposure to access points when assessing real exposure to RF-EMF. The exposure metric defined in this paper is built upon dose. It quantifies real average exposure of a population in a given geographical area by taking into account life segmentation data (usages, postures, traffic). Such exposure assessment is important on one hand for public information on real exposure induced by RF communication systems (today, most information is relative to maximum exposure assessed in worst-case scenarios) and on the other hand for epidemiological studies such as case-control MOBI-KIDS study [Calderon et al., 2014; Sadetzki et al., 2014] and the cohort COSMOS study [Schüz et al., 2011] that are looking for the mean or cumulative exposure of whole body or specific organs such as the brain. This metric also allows network management tools to minimize realistic exposure over the population in an area.

The objective of this paper is to propose a new exposure metric named Exposure Index (EI) assessing global average exposure of a population induced by both personal devices and networks' base station antennas and access points. Minimization of the EI is intended to be a new key performance indicator (KPI) for future wireless cellular networks. The purpose is to obtain a number that represents reallife exposure of a population in an area produced by a wireless cellular network. By considering EI as an average value over different contributing parameters, EI will enable evaluation of the contribution of each parameter to derive measures to lower the EMF exposure in an area. The concept of EI will be applied for the first time on real use cases to show its usability.

\section{DEFINITION OF A NEW METRIC: THE EI}

\section{Concept}

EI reflects global EMF exposure of a population to a given wireless cellular network (or set of networks). It does not take into account exposure induced by other RF sources such as Frequency Modulation radio or digital terrestrial television transmitters.

It covers exposure of a population during a given time frame in a given area incurred by a wireless cellular network as a whole, aggregating downlink (DL) exposure induced by base stations and access points and the uplink (UL) exposure incurred by all individual wireless communication devices. The downlink exposure can be subdivided in exposure due to base stations and access points and exposure due to devices operated by other users nearby.

To assess the realistic exposure of a population, many parameters influencing exposure need to be taken into account in the EI: age (adult and child exposure are different [Conil et al., 2008; Wiart et al., 2008]), posture [Nagaoka and Watanabe, 2008], usage, technology, environment, and more.

In brief, EI is a transfer function of a highly complex set of data, aggregated in a chain of exposure (Fig. 1) into a single parameter, understandable, acceptable, and usable for all stakeholders, from the general public to regulatory bodies.

Beyond the time parameter, possible scenarios can include one, several, or all links of the chain. Different exposure scenarios are considered and aggregated, thereby, determining EI. 


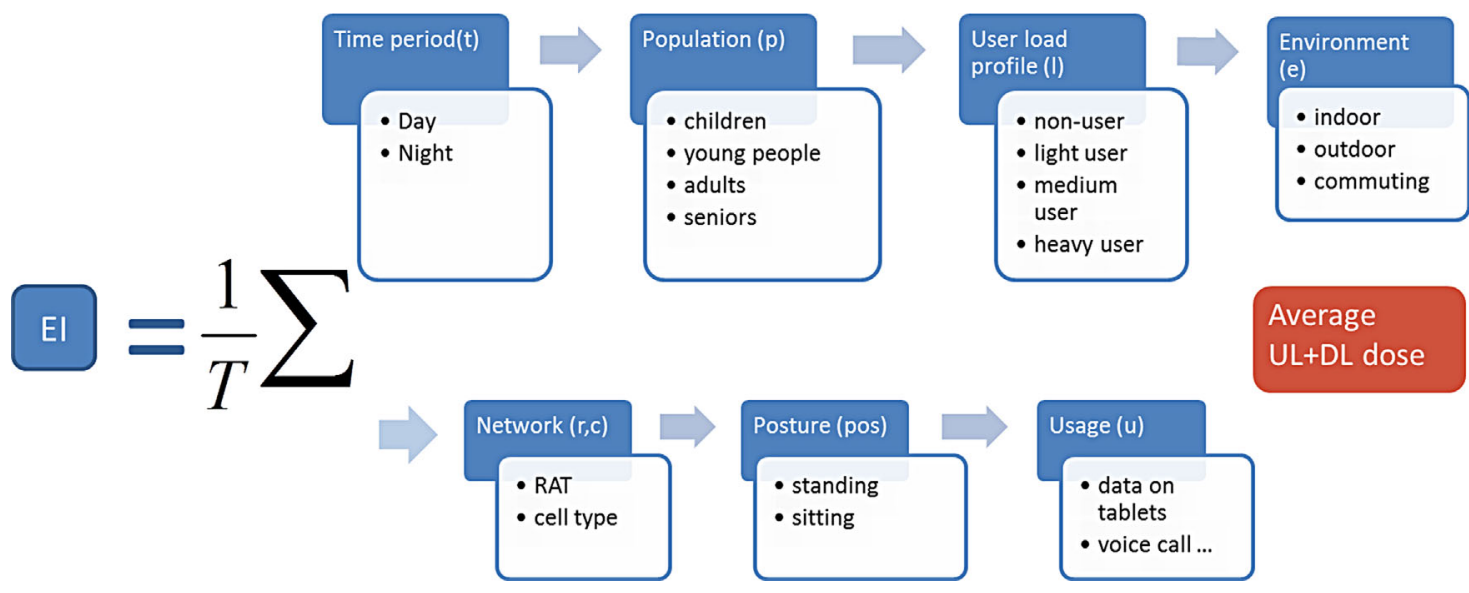

Fig. 1. El chain of exposure.

\section{Mathematical Formalization}

EI equation. EI can be calculated for different types of geographical areas, being typically urban, suburban, or rural areas. Urban, suburban, and rural wireless networks are different and solutions to reduce EMF exposure in an urban area may be different than solutions to reduce it in a rural one. This is why we chose to differentiate urban from suburban and rural areas [Joseph et al., 2008; Gati et al., 2009].

The general formulation of EI contains a set of technical parameters, as described below. The number of values, classes, or settings of each parameter depends on the level of detail of available data and level of achievable complexity in terms of calculation. For a given geographical area, EI takes the following into account (Fig. 1): time period $(t)$ : configurations of the network and of usages depend on time of day (power density will be higher during rush hours); population $(p)$ : segmented in different categories, as different population categories will have different life segmentations and different usages of wireless devices, e.g., children (less than 15 years old), young people (15-29), adults (30-59), and seniors (60 and older); different user load profiles $(l)$ : wireless device usages will be dramatically different depending on the profile, and as repartitions of user profiles will also be different depending on the population category (e.g., heavy, medium, light, or non-users); environment (e): indoor (office, home), outdoor, and in transportation (bus, car, subway etc.); different available Radio Access Technologies (RATs) (r): e.g., 2G (900 and $1800 \mathrm{MHz}), 3 \mathrm{G}, 4 \mathrm{G}, \mathrm{WiFi}$; the number of considered RATs depends on the scenario; different cell types $(c)$ : macro, micro, pico, and femto cells; the accessibility to different cell types depends on scenario; posture (pos): sitting, standing; different body postures will lead to different absorption rates in the human body; and usage ( $u$ ): a device (e.g., mobile, PC, laptop) and its usage (e.g., voice call, data).

The building block in exposure assessment is SAR expressed in $\mathrm{W} / \mathrm{kg}$. SAR will depend on morphology and posture of the user and on the position and distance of the source with respect to the user. As part of LEXNET, a set of numerical dosimetric simulations have been performed to fill out a matrix of raw normalized SAR values. These SAR values can be whole-body or localized SAR values. In the framework of LEXNET, we were interested in evaluating whole-body SAR values for different users, different postures and different usages, limiting these usages to the tablet usage, laptop usage, and to mobile phones close to the head or in data usage position. We wanted to use EI to reduce average exposure of a population to a wireless network. In terms of whole-body SAR, values holding the phone on the right or left side of the head or using earphones will not dramatically change a value. However, if we were considering using EI with localized SAR values for epidemiological studies, it would be relevant to differentiate right, left usages, or earphone usage because it would lead to different localized SAR values.

Network simulation tools, Information and Communication Technologies (ICT) usage data obtained through sensors inside the network and data on how different population categories segment their life (time spent indoor, outdoor, commuting), will then provide the levels to apply to the raw SAR matrix.

Finally, EI shall be calculated by crossing the database of raw SAR values with the set of configurations of exposure 


$$
E I^{\mathrm{SAR}}=\frac{1}{\mathrm{~T}} \sum_{t}^{N_{T}} \sum_{p}^{N_{P}} \sum_{e}^{N_{E}} \sum_{r}^{N_{R}} \sum_{c}^{N_{C}} \sum_{l}^{N_{L}} \sum_{\text {pos }}^{N_{\mathrm{pos}}} f_{\mathrm{t}, \mathrm{p}, \mathrm{e}, \mathrm{r}, \mathrm{l}, \mathrm{c}, \mathrm{pos}}\left[\sum_{u}^{N_{\mathrm{U}}}\left(d^{\mathrm{UL}} \bar{P}_{T X}\right)+d^{\mathrm{DL}} \bar{S}_{\text {inc }}+d^{\mathrm{DL}, \text { closeddevices }} S_{\text {inc }}^{\text {DLclosed devices }}\right]\left[\frac{W}{k g}\right]
$$

where $\mathrm{EI}^{\mathrm{SAR}}$ is EI value, the average exposure of the population of the considered geographical area over the considered time frame T. SAR refers to wholebody SAR, organ-specific SAR, or localized SAR. $N_{T}$ is number of considered periods within considered time frame (e.g., single day); $N_{P}$ is number of considered population categories; $N_{E}$ is number of considered environments; $N_{R}$ is number of considered RATs; $N_{C}$ is number of considered cell types; $N_{L}$ is number of considered user load profiles; $N_{\text {pos }}$ is number of considered postures; and $N_{U}$ is number of considered usages with devices. $\overline{\mathrm{P}}_{\mathrm{TX}}$ is mean $\mathrm{TX}$ power transmitted by users' devices during period $t$, in usage mode $u$, connected to RAT $r$, in environment $e$. A TX power values map is given for the whole considered geographical area and average value is taken into account for EI evaluation; $\overline{\mathrm{S}}_{\text {inc }}$ is mean incident power density on the human body during period $t$, induced by RAT $r$, in environment $e$. A distribution of the incident power density for the whole considered geographical area is considered and the average value over this area is taken into account for EI evaluation. $S_{\text {inc }}^{\mathrm{DL} \text {,closeddevices }}$ is incident power density on the human body during period $t$, induced by a wireless device connected to RAT $r$ of a user in proximity to environment $e$. This term will be significant for people in proximity of users of a wireless device; for instance, in a crowded meeting room, in public transportation, etc. In the applications discussed in this paper, this term is neglected. We also remark that $S_{\text {inc }}^{\mathrm{DL} \text {,closeddevices }}$ depends on orientation of the user of the wireless device with respect to the body of people in its proximity. $d^{\mathrm{UL}}\left(\frac{W s}{\mathrm{~kg}} / \mathrm{W}\right)$, $d^{\mathrm{DL}, \text { closeddevices }}\left(\frac{W s}{\mathrm{~kg}} / \frac{\mathrm{W}}{\mathrm{m}^{2}}\right)$, and $d^{\mathrm{DL}}\left(\frac{W s}{\mathrm{~kg}} / \frac{\mathrm{W}}{\mathrm{m}^{2}}\right)$ are normalized raw dose values for UL, DL from the user in the proximity, and DL from base stations and access points, respectively, all multiplied by time spent in configuration; and $f_{t, p, e, r, l, c, p o s}$ is the fraction of the total population that corresponds to population category $p$, user load profile $l$, in posture pos, connected to RAT $r$, for cell type $c$, in environment $e$, during time period $t$.

It is a choice to give an absolute value for EI. Of course, it does not prevent us mentioning considered duration as it is important to know if the given value was averaged over $24 \mathrm{~h}, 1$ week, or 1 month. Dividing by $T$ allows first overcoming time but above all, from the point of view of acceptance by stakeholders or the general public, it is more appropriate to use $\mathrm{W} / \mathrm{kg}$ for the EI unit as people are familiar with this unit used for SAR levels indicated when buying wireless devices.

Next, we will explain different terms used in the EI formula in more detail.

\section{Coefficients $d^{\mathrm{UL}}$ and $d^{\mathrm{DL}}$}

The coefficient $d^{\mathrm{UL}}$ is associated with exposure induced by the uplink and expressed as an absorbed dose normalized to a transmitted power of $1 \mathrm{~W}$ :

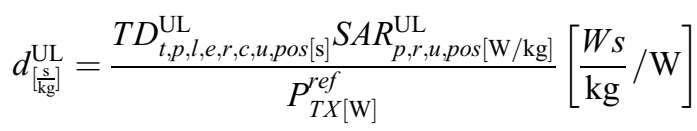

where $T D_{t, p, l, e, r, c, u, p o s}^{\mathrm{UL}}$ is time duration of the UL traffic of usage $u$, and a user profile load $l$, when connected to RAT $r$, operating in cell type $c$, in environment $e$, for population category $p$, in posture pos, during time period of the day $t$. $\frac{S A R_{,, r u, p o s}^{\mathrm{UL}}}{P_{T X}^{r e f}}$ can be whole body or an organspecific or tissue-specific SARvalue for usage $u$ and posture pos, in frequency band of RAT $r$, and population category $p$, calculated for an incident emitted power of $P_{T X}^{r e f}$ and normalized to this power. The coefficient $d^{D L}$ is associated with the exposure induced by downlink and also expressed as an absorbed dose normalized to an incident power density of $1 \mathrm{~W} / \mathrm{m}^{2}$ :

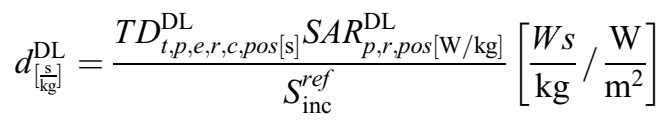

where $T D_{t, p, e, r, c, p o s}^{\mathrm{DL}}$ is time duration of posture pos, when connected to RAT $r$, operating in cell type $c$, in environment $e$, for population $p$, during time period of the day $t$. $\frac{S A R_{p, r}^{\mathrm{DL}} \text { pos }}{S_{R X \text { inc }}^{\text {ref }}}$ can be whole body or an organspecific or tissue-specific SARvalue induced by the base station or access points of RAT $r$, in population $p$, for posture pos, normalized to received power density $S_{\text {inc }}^{r e f}$.

\section{Transmitted Power $\overline{\boldsymbol{P}}_{T X}$ and Incident Power Density $\bar{S}_{i n c}$}

$\bar{P}_{T X}$ is the average power transmitted by the device in busy mode. It should be noted that, even in 
idle mode (not for active communication), devices transmit some power from time to time (e.g., to stay synchronized with the network) but exposure induced in idle mode is negligible in the examples of the further sections as it is based on rare events.

$\overline{\mathrm{S}}_{i n c}$ is average power density incident on the human body from base stations of the RAT and cell type considered. The incident power density is assessed not only for users of mobile devices, but also for non-users. It is assumed that the usage pattern of the user considered in the EI formula does not influence the average incident power density. From a theoretical point of view, $\overline{\mathrm{S}}_{i n c}$ is average incident power density integrated over all frequency bands of the RAT and cell type considered. From a practical point of view, $\overline{\mathrm{S}}_{i n c}$ can be assessed directly from spectrum analyzer measurements, dosimeters, simulations, and indirectly from received power on a user device or in a drive test measurement.

$\bar{P}_{T X}$ and $\overline{\mathrm{S}}_{i n c}$ average out the instantaneous variations of transmitted power and incident power density that arise during a communication. These variations occur when the user is static or moving over a very small distance and are caused by different phenomena (power regulation, small-scale fading, resource allocation, user traffic variations, etc.)

For each given location, for each period of time, for each traffic type, averaged values of transmitted powers and incident power densities are calculated. Thus, the duty cycle of a system (e.g., WiFi) is accounted for.

\section{El Computation: Data Sources}

Different sources of information are required for the computation of EI. We considered life segmentation data, Information and Communication Technologies (ICT) usage data, SAR data, and $\bar{P}_{T X}$ and $\overline{\mathrm{S}}_{\text {inc }}$ data.

Life segmentation data. It gives information on how people spend their time. It gives information on how to segment a day when applying the EI formula. This kind of data can be extracted from up-to-date life segmentation surveys (Table 1).

ICT usage data. These type of data (usage of mobile phones for voice call or data, usage of tablets, PC etc.) are obtained through measurements of network Key Performance Indicators (KPIs), such as uplink and downlink data traffic volumes, number of voice calls, duration of each voice call, etc.

SAR reference data. Reference SAR data can be provided by numerical three-dimensional (3D) electromagnetic simulation softwares using anatomical human body models such as models from the Virtual Family [Christ et al., 2010].

$\overline{\boldsymbol{P}}_{T X}$ and $\overline{\mathbf{S}}_{\text {inc }}$ data. Emitted power values and incident power density can be evaluated by wireless network planning tools, and by measurements of $P_{T x}$ using drive test tools, whereas incident power density can be measured using dosimeters and spectrum analyzer with triaxial probe.

With all the data described above and for a userdefined scenario, EI can be calculated.

\section{LEXNET EI}

\section{Input Parameters}

Table 2 details the chosen segmentation parameters of the EI in the framework of the LEXNET project.

To be able to evaluate EI in different scenarios, tools, models, and measurement equipment available within the LEXNET project consortium were used.

For life segmentation data, up-to-date life segmentation surveys collected in the different participating countries were used to extract information on how different categories of the population segment their daily lives.

TABLE 1. Example of Life Segmentation for Different Categories of the Population Over One Day

\begin{tabular}{|c|c|c|c|}
\hline Time consumption $(\mathrm{h})$ & Adults & Children & Seniors \\
\hline Gainful work, study & $5: 00$ & $4: 40$ & 0:05 \\
\hline Domestic work & $3: 00$ & $1: 15$ & 4:00 \\
\hline Travel & $1: 30$ & $1: 20$ & $0: 50$ \\
\hline Sleep & $8: 15$ & 9:00 & $8: 45$ \\
\hline Meals, personal care & $2: 15$ & $2: 45$ & $3: 30$ \\
\hline Free time indoor (TV, socializing, reading, internet surfing, etc.) & $3: 00$ & $4: 00$ & $4: 30$ \\
\hline Free time outdoor (sports, gardening, hiking, etc.) & $1: 00$ & $1: 00$ & $2: 20$ \\
\hline Total & $24: 00$ & 24:00 & $24: 00$ \\
\hline
\end{tabular}

Data obtained from HETUS survey [2006] and INSEE survey [2011]. 
TABLE 2. LEXNET Segmentation Parameters

\begin{tabular}{llllllll}
\hline Time & Population & User Profile & Environment & RAT & Cell Type & Posture & Usage \\
\hline Day & Children & Heavy & Indoor & $2 \mathrm{G}$ & Macro & Standing & Voice, mobile \\
Night & Young people & Medium & Outdoor & $3 \mathrm{G}$ & Micro & Sitting & Data, mobile \\
- & Adults & Light & Commuting & $4 \mathrm{G}$ & Pico & - & Data, Tablet \\
- & Seniors & Non-user & - & WiFi & Femto & - & Data, Laptop, on laps \\
- & - & - & - & - & - & - & Data, Laptop, on a desk \\
\hline
\end{tabular}

The operators Orange (France) and Telekom Serbia (Serbia), involved in the LEXNET project, provided ICT usage data.

Reference SAR data were computed using 3D electromagnetic simulation platforms based on the Finite Difference Time Domain (FDTD) method [Taflove and Hagness, 2000]. SAR values were calculated for far-field and near-field exposure for two anatomical human body models of the Virtual Family [Christ et al., 2010]: Duke, a 34-year-old male and Eartha, an 8-year-old girl. Two postures (standing and sitting) and three usages (mobile phone close to head, mobile phone or tablet for data and laptop usage) were selected.

Wireless network planning tools (Volcano Suite by Siradel, Rennes, France; Orange and Telekom, Serbia's own wireless network planning tools; WHIPP tool by IMinds, Ghent University, Ghent, Belgium) and personal exposimeter measurements provide average transmitted and received power values for a given area at a given location, for a given usage of devices, at a given period of the day. Dosimeter measurements consisted of two types of measurements: wearable and fixed dosimeters. In situ measurements were executed close to the end-user body, thanks to the wearable version of the dosimeter. Fixed dosimeters are planned to be deployed in a dense sensors network of a "smart" city.

All these data were used to evaluate EI in the two examples detailed in the next sections.

\section{EVALUATION OF EI IN PHONE CALL SCENARIOS}

EI was first evaluated for four independent subscenarios (using GSM/UMTS), with each scenario considering one specific environment, a limited timeperiod, one category of the population, one network, and one usage. In the next section, a scenario with long term evolution (LTE) technology is considered.

\section{Description of Sub-Scenarios}

EI was evaluated for four different sub-scenarios: two scenarios considering exposure of people commuting in a train and two scenarios considering exposure of people located indoors (Fig. 2). The population consisted of adults, making UMTS (indoor) or GSM1800 (train) phonecalls with the phone on the right side of the head. As illustrated in Figure 2, scenario 1 considers an indoor macrocell connection. Scenario 2 considers an indoor small cell connection, scenario 3 a macrocell connection in a train, and scenario 4 a small cell connection in a train.

\section{Scenario Description}

Common exposure configuration parameters for the four sub-scenarios are shown in Table 3. Table 4 lists scenario specific parameters: environment, cell type, RAT, and posture. User profiles were created to correspond with average phone call durations described in Mohler et al. [2009].

Then, depending on scenario, environment, cell type, RAT, and posture were different (Table 4).

If we consider the coefficients of the EI equation, one sub-scenario corresponds to: $N_{T}=1, N_{P}=1$, $N_{E}=1, N_{R}=1, N_{C}=1, N_{L}=4, N_{\text {pos }}=1$, and $N_{U}=1$. We are considering a limited time period $(1 \mathrm{~h}$ during

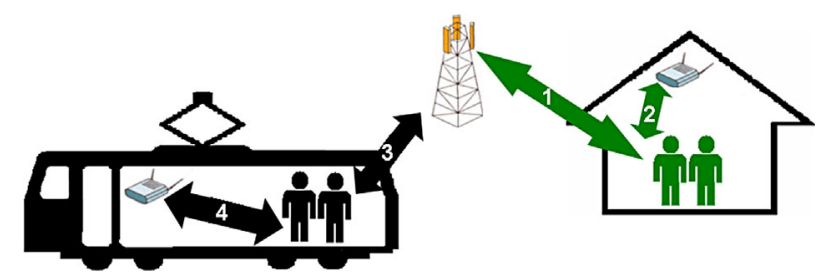

Fig. 2. Illustration of four deployment sub-scenarios.

TABLE 3. Exposure Configuration for Four Sub-Scenarios

\begin{tabular}{ll}
\hline Time period & $1 \mathrm{~h}$ during afternoon \\
\hline Population category & Adults \\
User profiles & $10 \%$ heavy users: $30 \mathrm{~s}$ usage \\
& $50 \%$ moderate users: $10 \mathrm{~s}$ usage \\
& $25 \%$ light users: $3 \mathrm{~s}$ usage \\
& $15 \%$ no usage: $0 \mathrm{~s}$ usage \\
Usage & Voice, mobile phone on right side of head
\end{tabular}


TABLE 4. Configurations Specific to Each Sub-Scenario

\begin{tabular}{lllll}
\hline Scenario & Environment & Cell type & RAT & Posture \\
\hline 1 & Indoor & Macro & UMTS & Standing \\
2 & Indoor & Small: Femtocell & UMTS & Standing \\
3 & Train & Macro & GSM1800 & Sitting $^{\mathrm{a}}$ \\
4 & Train & Small: Picocell & GSM1800 & Sitting $^{\mathrm{a}}$ \\
\hline
\end{tabular}

${ }^{\mathrm{a}}$ For a sitting posture, the same normalized SAR values as for a standing posture are used.

the afternoon, $T=3600 \mathrm{~s}$ ), only adults and only one device and one usage (mobile phone in a voice call) (Table 3).

\section{Input Parameters}

For calculation of EI, several input parameters are needed: reference SAR values, median transmitted power values $\bar{P}_{T X}$, and median incident power density values $\bar{S}_{R X \text { inc }}$ (Table 5).

The power (density) values used for the train scenarios (3-4) and indoor macrocell scenario (1) were derived from measurements in a train [Aerts et al., 2013] and in an office building (Zuiderpoort building, Ghent, Belgium) [Plets et al., 2014], respectively. For the indoor femtocell scenario (2), accurate simulation values from the WHIPP tool, a heuristic indoor network calculator, and planner [Plets et al., 2012], were used. In the considered building, a femtocell with an Equivalent Isotropically Radiated Power (EIRP) of $7 \mathrm{dBm}$ was installed. A different femtocell EIRP can lead to a largely different EI. Reference SAR values were taken from Lauer et al. [2013] and applied to the indoor and train scenario, for an adult standing, using the phone on the right side of the head. Figure 3 shows the considered building. Since the measured macrocell values $\left(\bar{S}_{R X \text { inc }}\right.$ and $\left.\bar{P}_{T X}\right)$ were not recorded in the smaller and more enclosed central areas of the building floor (toilets, kitchen, shed etc.), femtocell predictions will be limited to the

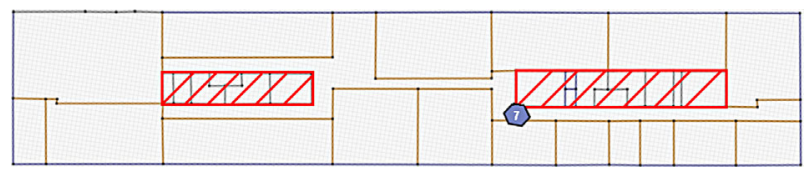

Fig. 3. Ground plan of considered floor $(90 \times 17 \mathrm{~m})$ of the office building that is simulated. Femtocell base station location is indicated with hexagon $(\mathrm{EIRP}=7 \mathrm{dBm})$.

nonshaded areas around the center in Figure 3. For femtocell values, locations within $50 \mathrm{~cm}$ of the base station are discarded, assuming that people stay at least half a meter away from base stations. For indoor simulations, a subscenario is also considered, for which a $20 \mathrm{~dB}$ worse macrocell connection is assumed for the same building floor. This could correspond to a building with a penetration loss that is $20 \mathrm{~dB}$ higher than before, or a building located farther from the macrocell base station (path loss increase of $20 \mathrm{~dB}$ ). Table 5 shows that the assumed $\bar{P}_{T X} / \bar{S}_{R X \text { inc }}$ values in case of a "worse connection" are indeed $20 \mathrm{~dB}$ higher/ lower.

\section{RESULTS}

In the following, EI results are discussed for different scenarios in the indoor office building and in a train.

\section{Indoor}

Figure 4a compares EI for scenarios 1 and 2 for the indoor office building. Total EI for each scenario is listed above the figures. From an exposure-point-of-view, the indoor femtocell scenario (scenario $2, \mathrm{EI}=1.58 \times 10^{-8}$ $\mathrm{W} / \mathrm{kg}$ ) is a factor 28 worse than the indoor macrocell scenario (scenario $1, \mathrm{EI}=5.64 \times 10^{-10} \mathrm{~W} / \mathrm{kg}$ ). The main EI contribution in scenario 2 is the high DL exposure originating from the femtocell $\left(1.55 \times 10^{-8} \mathrm{~W} / \mathrm{kg}\right)$. The scale in Figure 4a has been adjusted: the bar that represents the DL femto indoor contribution is in reality

TABLE 5. Reference SAR Values and Average Transmitted Power and Observed Power Density Values

\begin{tabular}{|c|c|c|c|c|}
\hline & \multicolumn{2}{|l|}{ UMTS } & \multicolumn{2}{|l|}{ GSM1800 } \\
\hline & Femto, indoor & Macro, indoor & Pico, in train & Macro, in train \\
\hline$S A R_{p, r, p o s}^{D L}$ & $0.003 \mathrm{~W} / \mathrm{kg}$ & $0.003 \mathrm{~W} / \mathrm{kg}$ & $0.003 \mathrm{~W} / \mathrm{kg}$ & $0.003 \mathrm{~W} / \mathrm{kg}$ \\
\hline$S A R_{p, r u, p o s}^{U L}$ & $0.00495 \mathrm{~W} / \mathrm{kg}$ & $0.00495 \mathrm{~W} / \mathrm{kg}$ & $0.00495 \mathrm{~W} / \mathrm{kg}$ & $0.00495 \mathrm{~W} / \mathrm{kg}$ \\
\hline $\bar{P}_{T X}^{p, r, a, p o s}$ & $2.85 .10^{-7} \mathrm{~W}$ & $2.66 .10^{-5} \mathrm{~W}$ & $1.10^{-3} \mathrm{~W}^{\mathrm{a}}$ & $6.3095 .10^{-2} \mathrm{~W}$ \\
\hline $\bar{P}_{T X}($ worse connection $)$ & $2.85 .10^{-7} \mathrm{~W}$ & $2.66 .10^{-3} \mathrm{~W}$ & N/A & N/A \\
\hline $\bar{S}_{R X}$ & $5.18 .10^{-6} \mathrm{~W} / \mathrm{m}^{2}$ & $8.15 .10^{-8} \mathrm{~W} / \mathrm{m}^{2}$ & $1.09 .10^{-4} \mathrm{~W} / \mathrm{m}^{2}$ & $4.4 .10^{-8} \mathrm{~W} / \mathrm{m}^{2}$ \\
\hline $\bar{S}_{R X}($ worse connection $)$ & $5.18 .10^{-6} \mathrm{~W} / \mathrm{m}^{2}$ & $8.15 .10^{-10} \mathrm{~W} / \mathrm{m}^{2}$ & N/A & N/A \\
\hline
\end{tabular}

${ }^{\mathrm{a}}$ Lowest possible value for GSM1800. 

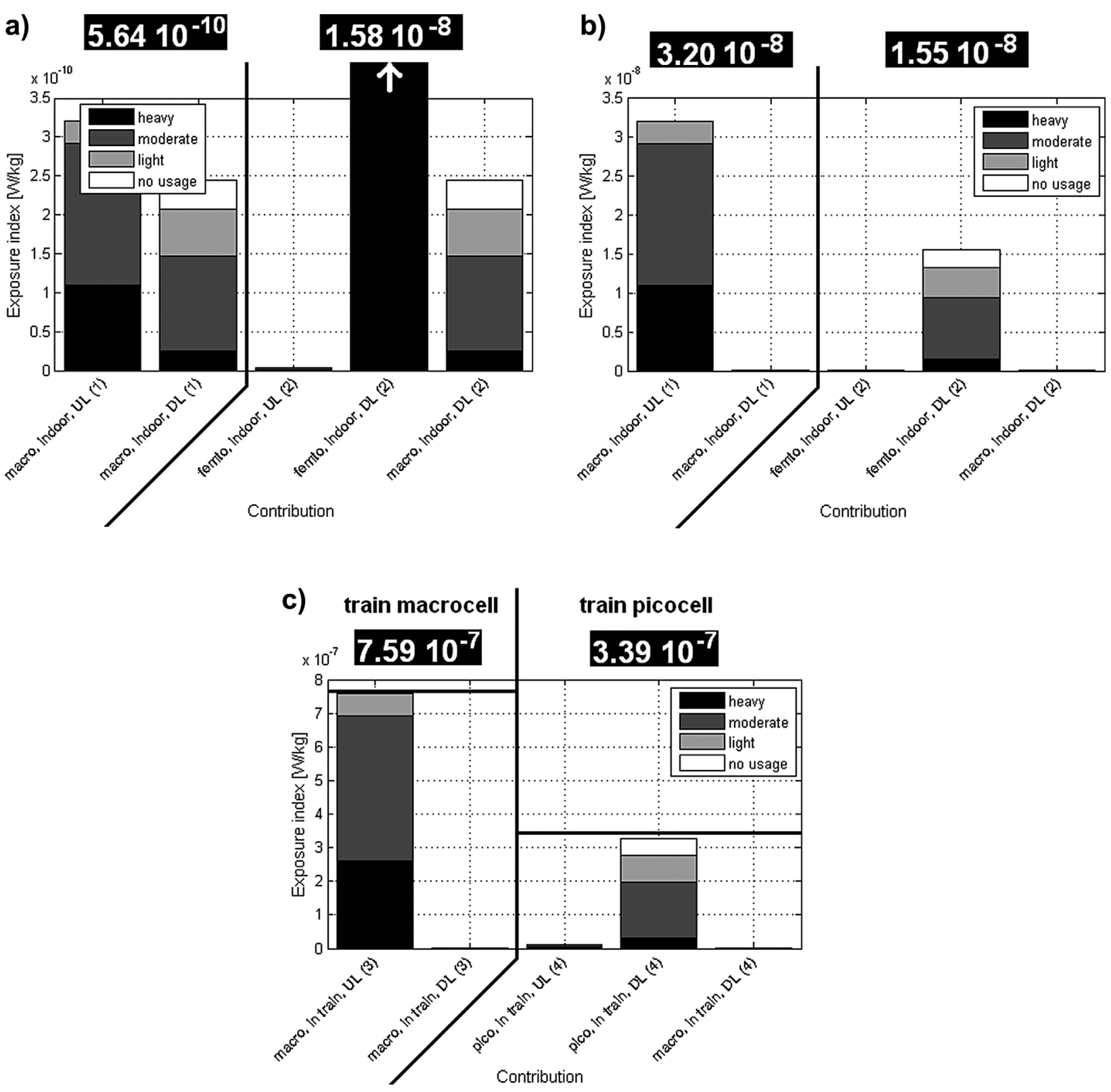

Fig. 4. Comparison of contributions to whole-body El for (a) indoor scenarios 1 and 2 in the considered building, (b) indoor scenarios 1 and 2 in this building with $20 \mathrm{~dB}$ worse connection quality, and (c) train scenarios 3 and 4. Total El levels for each scenario are indicated with the horizontal line. El values are shown in $\mathrm{W} / \mathrm{kg}$.

44 times the length of the Y-scale. There are several reasons why installation of a femtocell is not beneficial in this case. First, EI contributions of the macrocell are almost equal for UL and DL, which is optimal from an exposure-point-of-view. Second, femtocell EIRP is chosen quite high $(7 \mathrm{dBm})$ : despite the good macrocell connection (average value of $-69.25 \mathrm{dBm}$ ), still $77 \%$ of the DL fields are higher in the femtocell case. Third, a femtocell installation has the disadvantage that observed power densities on a building floor due to a femtocell base station are less homogeneously distributed than fields due to a (more distant) macrocell base station. As people are assumed to, on average, reside an equal time at each location on the building floor (except shaded areas and locations closer than $50 \mathrm{~cm}$ from the base station), locations close to the femtocell contribute a lot to EI. When people approach a femtocell, the absorbed exposure dose increases in a more-than-linear way. Macrocell base stations have the advantage that UL/DL fields are more homogeneously distributed over the 
building floor. It should also be noted that the higher the UL usage, the more the femtocell scenario will benefit, compared to the macrocell scenario (lower EI). However, in the considered case, the UL usage times would have to increase by a factor of 48 to yield a total EI (macrocell scenario 1) that is equal to the EI of scenario 2 (femtocell scenario, $\mathrm{EI}=1.58 \times 10^{-8} \mathrm{~W} / \mathrm{kg}$ ).

We also considered a second case, where a less favorable macrocell case was considered (worse connection). It is assumed that the connection with the macrocell base station is now $20 \mathrm{~dB}$ worse than in the previous case. Figure $4 \mathrm{~b}$ compares EI for macrocell and femtocell deployments. Due to the worse connection (average received macrocell DL power of $-89.25 \mathrm{dBm})$, the macrocell EI is now completely determined by the UL contribution $\left(3.20 \times 10^{-8} \mathrm{~W} /\right.$ $\mathrm{kg}$ ), and the femtocell scenario (scenario $2, \mathrm{EI}=1.55$ $\times 10^{-8} \mathrm{~W} / \mathrm{kg}$ ) has an EI that is $48 \%$ of the macrocell EI, which makes it preferable over the macrocell deployment. Moreover, the observed power densities due to the femtocell are higher than the macrocell power densities at all locations (better QoS).

It can be concluded that installation of femtocell is not always recommended. For shorter UL usage times and/or better macrocell connection qualities, it could be advised to rely on the existing macrocell infrastructure. Also, when installing a femtocell, its EIRP should be adjusted to the size and physical properties of the building and should not be set at a needlessly high value.

\section{In the Train}

Figure $4 \mathrm{c}$ shows EI contributions for the train scenarios 3 and 4. Table 5 and Figure $4 c$ show that when comparing scenario 3 (train macrocell) with scenario 4 (train picocell), it is clear that the high transmit powers in the macrocell scenario cause a high EI (highest contributions to the EI). While the amount of "moderate users" is five times as high as the amount of "heavy users" (50\% vs. 10\%), their contribution to EI is only about $50 \%$ higher (left bar in Figure 4c). When using a small cell (picocell in scenario 4 in Figure 4c, right three bars), EI decreases by a factor of 2.2, but still remains more than 100 times higher than the worst indoor scenarios (scenario 1-2, see Table 5), due to the relatively high constant power density originated by the picocell. It can, therefore, be advised to dimension the RF output power of the picocell (here set at $17 \mathrm{dBm}$ ) well and not increase it needlessly.

\section{DISCUSSION}

Using a picocell in a train instead of relying on the macrocell reduces EI by a factor of 2.2 for the considered scenario. As already stated, it is advised not to needlessly increase the indoor base station's EIRP, as the picocell DL exposure can be the main contributor to total EI when deploying an indoor base station. For the considered building, using a femtocell instead of relying on the existing macrocell increased EI by a factor of 2.3. This is due to the location of the building, which allowed a good connection with the macrocell. When the connection quality with the macrocell becomes worse, installation of femtocells can be beneficial. This also counts for buildings where a low femtocell EIRP is sufficient to provide coverage in the building.

\section{EVALUATION OF THE EI FOR AN LTE DATA SCENARIO}

Assessment of EI may follow various methodologies depending on application and context, for instance: evaluation of a new technology implemented in a real test bed; pre-deployment optimization of the network design; optimization of a network configuration based on network monitoring data and user device measurements; assessment of EMF exposure from a sensor network etc. Radio-planning techniques are used here to illustrate EI computation and clarify the role of the different involved components in Figure 1 (people categories, user traffic models, transmit UL powers, DL incident power densities, reference SAR values, etc.).

\section{Description of the Scenario}

EI was computed in a real urban area-part of the seventh district of Paris - represented by a high resolution 3D building and map data. For simplicity of the demonstration, only a 1-RAT macro-cell network was considered, based on LTE technology (Fig. 5).

Macro Base Stations (BS) are deployed in a hexagonal manner with an inter-site distance of $450 \mathrm{~m}$. Positions, heights, and transmitted powers of the base stations were selected to be representative of a typical macrocell deployment in an urban environment. The area covered by the 12 central macro sectors defines the study area, as shown in Figure 5. Note that base stations outside this study area are also included in the simulations to generate an accurate interference pattern.

We considered an LTE Frequency Division Duplexing (FDD) $2 \times 10 \mathrm{MHz}$ bandwidth system that operates in the $2600 \mathrm{MHz}$ frequency band. Additional parameters such as BS and User Equipment (UE) transmit powers, antenna parameters etc. and are detailed in Table 6. Users were assumed to be 


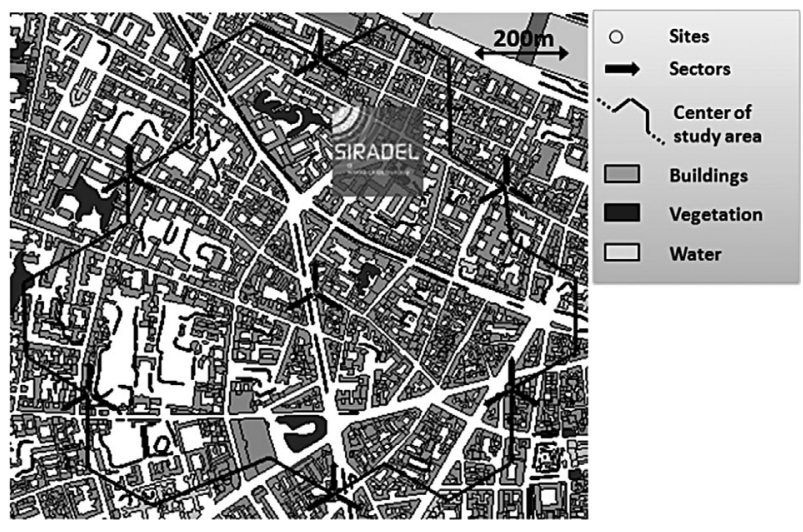

Fig. 5. Macrocell deployment and study area in Paris seventh district.

uniformly distributed in the study area. An indoor/ outdoor ratio defines the percentage of users located inside buildings (the indoor/outdoor ratio is set to 80/ $20 \%$, corresponding to ratios detailed in Table 8 ).

\section{El Equation Terms}

In the following, each term of Eq. (1) is explained for the considered scenario. A quite simple segmentation has been chosen in this example to illustrate the feasibility of the EI in an end-to-end computation. Two time periods were considered $\left(N_{T}\right.$ $=2$ ): the day from 8 a.m. to 6 p.m. ( $10 \mathrm{~h}$ total) and the night from 6 p.m. to 8 a.m. (14 h total). We considered the population above 15 years old. Three population categories were considered as shown in Table 7. The population density of the seventh district of Paris was estimated at 14,360 inhabitants per $\mathrm{km}^{2}$ in 2009 (Cartesfrance.fr).

Usage profiles were set depending on age: for example, young people are using mostly messaging while older people are using more voice calls. To represent the different usage profiles depending on age, the population was segmented into three categories: young people (between 15 and 29 years), adults (between 30 and 59 years), and seniors (over 60 years). Table 7 lists the percentages of people in each category.

We considered $N_{T}=2$ environments, indoor and outdoor (Table 8). Activities of everyday life for each population category have been analyzed in European time surveys [HETUS, 2000; TNS, 2010; INSEE, 2011]. We derived from these analyses the time spent indoors $(e=$ in) and outdoors $(e=$ out $)$ for each category on an average day (averaged over 1 year,

TABLE 6. Network Parameters for LTE Data Scenario

\begin{tabular}{|c|c|c|}
\hline Environment & Typical European Dense Urban envir & (Paris seventh district) \\
\hline \multirow[t]{3}{*}{ System } & Downlink and uplink & \\
\hline & LTE FDD & $2 \times 10 \mathrm{MHz}$ \\
\hline & Central frequency & $2600 \mathrm{MHz}$ \\
\hline \multirow[t]{6}{*}{ Macro layout } & Hexagonal site deployment & $\begin{array}{l}37 \text { sites corresponding to } 83 \text { macro cells; including } 12 \text { sites in the } \\
\text { center of the study area. Inter-site distance of } 450 \mathrm{~m} \text {. }\end{array}$ \\
\hline & $\begin{array}{l}\text { Nominal transmit power/Energy per } \\
\text { resource element }\end{array}$ & $40 \mathrm{~W} / 22.8 \mathrm{dBm}$ \\
\hline & Antenna & $\begin{array}{l}\text { Directional with } 14 \mathrm{dBi} \text { gain, } 6^{\circ} \text { electric down-tilt, two antennas } \\
\text { per sector. Average antenna height: } 30 \mathrm{~m} \text { above ground. }\end{array}$ \\
\hline & Noise figure & $2.5 \mathrm{~dB}$ \\
\hline & $\begin{array}{l}\text { Inter-cell Interference Coordination } \\
\text { (ICIC) }\end{array}$ & $\begin{array}{c}\text { Fractional frequency reuse scheme, } 5 \% \text { of total radio resources } \\
\text { being allocated to each sub-band, re-use factor of } 3 .\end{array}$ \\
\hline & UL power control (open loop) & $\begin{array}{c}\text { Path loss compensation factor }(\alpha): 1 \\
\text { Signal-to-interference plus noise ratio target: } 20.8 \mathrm{~dB}\end{array}$ \\
\hline \multirow[t]{3}{*}{ User equipment } & Max/Min transmit power & $23 /-40 \mathrm{dBm}$ \\
\hline & Antenna & $\begin{array}{l}\text { Omni-directional with } 0 \mathrm{dBi} \text { gain. Two antennas/user device. } \\
\text { Antenna height: } 1.5 \mathrm{~m} \text { above ground. }\end{array}$ \\
\hline & Noise figure & $9 \mathrm{~dB}$ \\
\hline \multirow[t]{2}{*}{ User traffic } & Average active user density & Depends on day/night \\
\hline & Distribution & $\begin{array}{l}\text { Uniform spatial distribution within the simulation area. Single } \\
\text { floor (at } 1.5 \mathrm{~m} \text { height). No user mobility. }\end{array}$ \\
\hline
\end{tabular}


TABLE 7. Repartition of Paris' Seventh District Population Depending on Age

\begin{tabular}{ll}
\hline Population category & Percentages (\%) \\
\hline Young people (15-29 y.o.) & 26 \\
Adults (30-59 y.o.) & 45 \\
Seniors (60+ y.o.) & 29 \\
\hline
\end{tabular}

TABLE 8. Repartition of Each Category of Population $p$ by Environment $e$ and Time Slot $t$

\begin{tabular}{|c|c|c|c|c|}
\hline & \multicolumn{2}{|l|}{$t=$ day } & \multicolumn{2}{|l|}{$t=$ night } \\
\hline & $e=$ in & $e=$ out & $e=$ in & $e=$ out \\
\hline $\begin{array}{c}p=\text { young } \\
\text { people }\end{array}$ & $\begin{array}{c}8 \mathrm{~h} 20 \mathrm{~min} \\
(83 \%)\end{array}$ & $\begin{array}{c}1 \mathrm{~h} 40 \mathrm{~min} \\
(17 \%)\end{array}$ & $\begin{array}{c}13 \mathrm{~h} 10 \mathrm{~min} \\
(94 \%)\end{array}$ & $\begin{array}{r}50 \min \\
(6 \%)\end{array}$ \\
\hline $\begin{array}{c}p=\text { adults } \\
(6.5 \%)\end{array}$ & $\begin{array}{r}8 \mathrm{~h} 15 \mathrm{~min} \\
(82.5 \%)\end{array}$ & $\begin{array}{r}1 \mathrm{~h} 45 \mathrm{~min} \\
(17.5 \%)\end{array}$ & $\begin{array}{c}13 \mathrm{~h} 05 \mathrm{~min} \\
(93.5 \%)\end{array}$ & $55 \mathrm{~min}$ \\
\hline $\begin{array}{c}p=\text { seniors } \\
(6.5 \%)\end{array}$ & $\begin{array}{c}7 \mathrm{~h} 35 \mathrm{~min} \\
\quad(70 \%)\end{array}$ & $\begin{array}{c}2 \mathrm{~h} 25 \mathrm{~min} \\
(30 \%)\end{array}$ & $\begin{array}{c}13 \mathrm{~h} 05 \mathrm{~min} \\
\quad(93.5 \%)\end{array}$ & $55 \mathrm{~min}$ \\
\hline
\end{tabular}

TABLE 9. Repartition of Users and Non-Users for Each Population Category

\begin{tabular}{llll}
\hline $\begin{array}{l}\text { User } \\
\text { profile }\end{array}$ & $\begin{array}{l}\text { Young people (15- } \\
29 \text { y.o.) }\end{array}$ & $\begin{array}{l}\text { Adults (30-59 } \\
\text { y.o.) }\end{array}$ & $\begin{array}{l}\text { Seniors (over } \\
60 \text { y.o.) }\end{array}$ \\
\hline Non-users & $33 \%$ & $57 \%$ & $91 \%$ \\
Users & $67 \%$ & $43 \%$ & $9 \%$ \\
\hline
\end{tabular}

considering weekdays, weekends, and holidays) as summarized in Table 8.

We considered an LTE network with a macrocell deployment as described in the previous section. Only one network usage was considered: a data traffic usage. The device was assumed to be a mobile phone, while the user was in a standing posture. Considering the existence of four telecom operators in France, only $25 \%$ of the seventh district population was assumed to be using this LTE macro network. In this example, we considered two user profiles: moderate user and non-user. For each population category, we derived from Bigot et al. [2013], proportions of users and non-users of mobile phones for data traffic (Table 9).

Parameters for the moderate user profile were the same for all population categories: we assumed a daily data traffic per active user of $66 \mathrm{MB}$ [Cisco, 2015], a DL/UL ratio of $90 / 10 \%$ (this ratio was evaluated from data collected through measurements of KPIs by sensors inside the French Orange network) and a day/night ratio of $43 / 57 \%$. From Cisco [2015], only $2.9 \%$ of users were considered as $4 \mathrm{G}$ users (in 2013, $2.9 \%$ of connections were 4G).

Reference SAR values were derived from numerical FDTD dosimetric simulations, as part of LEXNET project.

Incident $\bar{S}_{R X i n c}$ power densities and transmitted $\bar{P}_{T X}$ powers were calculated using the network planner simulation tool Volcano Suite (Siradel, Rennes, France) with assumptions detailed previously as input parameters.

Figures 6 and 7 illustrate, respectively, average User Equipment Tx power calculated over the seventh Paris district during the day for an LTE data traffic and average incident field strength evaluated during day or night (values during day or night time were quasi identical).

Because average active LTE user density is very low (41 users $/ \mathrm{km}^{2}$, consequence of the $2.9 \%$ LTE connections hypothesis), user traffic is less than $1 \%$ of available resources and we can see in Figure 6 (left
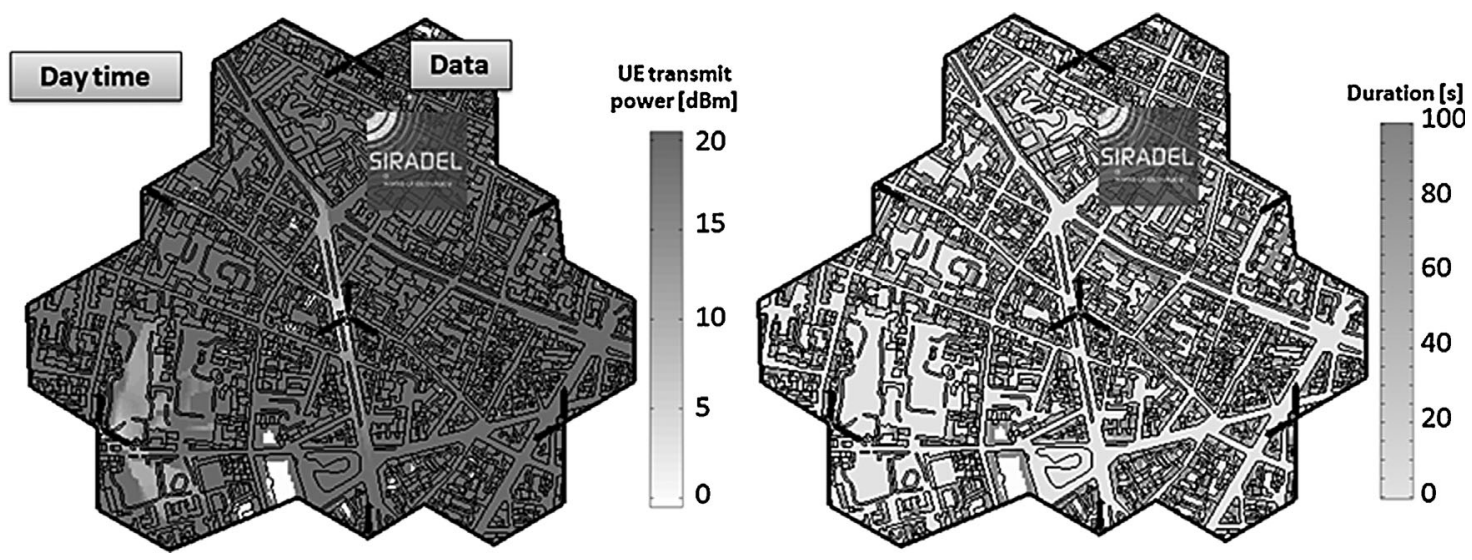

Fig. 6. Map of Tx power ( $\mathrm{dBm})$ calculated indoors at ground floor and outdoor during the day (on the left) and map of daily average transmission duration (s) (right). 


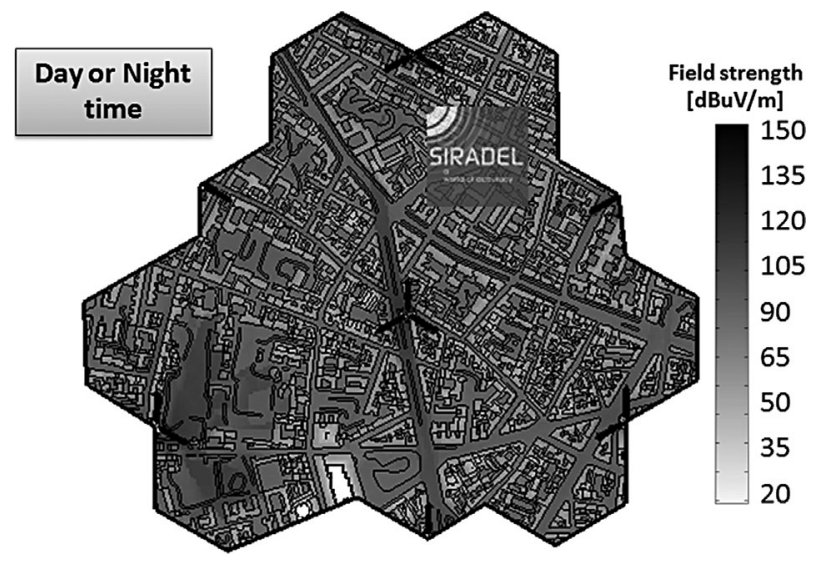

Fig. 7. Map of Rx field strength $(\mathrm{dB} \mu \mathrm{V} / \mathrm{m})$ calculated indoors at ground floor and outdoors during the day or the night.

figure) that the calculated average Tx power during the day was almost at its maximum whatever the location. In Figure 6 (right figure) we can observe that highest durations were obtained indoors, which is logical as people use wireless equipment for data mostly indoors. Figure 7 shows that Rx field strength is highly dependent on base station network configuration. Highest downlink Rx field strengths were observed outdoors in locations close to base stations.

Aggregating everything, we obtained the following value for the EI (based on whole-body SAR) of the over 15 years old population of the seventh district of Paris, considering a macrocell LTE network: $\mathrm{EI}^{\mathrm{WBSAR}}=3.19 \times 10^{-7} \mathrm{~W} / \mathrm{kg}$.

This average value over an entire region should, of course, not be compared to ICNIRP limits. The aim was to use it as a KPI for network optimization in terms of both downlink and uplink exposures to EMF.

\section{CONCLUSION}

In this paper, a new metric to evaluate EMF exposure induced by a wireless telecommunication network has been introduced. This metric, EI, aims at evaluating averaged exposure of a population in a given area induced by both user devices and network equipment. EI is built on segmentations in time, people, environments, Radio Access Technologies, cell layers, usages, and user profiles. In the paper, simple phone call scenarios (indoor office, in train) and a more advanced macro urban LTE data scenario illustrate the feasibility of an end-to-end calculation of EI. In the framework of the LEXNET project, different technological and network architecture solutions will be studied to minimize EI.

\section{REFERENCES}

Aerts S, Plets D, Verloock L, Martens L, Joseph W. 2013. Assessment and comparison of RF exposure dose in femtocell and macrocell scenario. Radiat Prot Dosim 162:236-243.

Bigot R, Croutte P, Daudey E. 2013. La diffusion des technologies de l'information et de la communication dans la société française. CREDOC report $\mathrm{n}^{\circ} \mathrm{R} 297$, November.

Calderon C, Addison D, Mee T, Findlay R, Maslanyj M, Conil E, Kromhout H, Lee AK, Sim MR, Taki M, Varsier N, Wiart J, Cardis E. 2014. Assessment of extremely low frequency magnetic field exposure from GSM mobile phones. Bioelectromagnetics 35:210-221.

Cartesfrance. fr Website. Paris 7th District information. Information available at: http://www.cartesfrance.fr/ [Last accessed 30 March 2015].

Christ A, Kainz W, Hahn EG, Honegger K, Zefferer M, Neufeld E, Rascher W, Janka R, Bautz W, Chen J, Kiefer B, Schmitt P, Hollenbach HP, Shen J, Oberle M, Szczerba D, Kam A, Guag JW, Kuster N. 2010. The Virtual Family_Development of surface-based anatomical models of two adults and two children for dosimetric simulations. Phys Med Biol 55:23-38.

Cisco. 2015. Cisco Visual Networking Index: Global Mobile Data Traffic Forecast Update 2014-2019 White paper. Available from: http:/www.cisco.com/c/en/us/solutions/collateral/ service-provider/visual-networking-index-vni/white_paper_c 11-520862.html [Last accessed 12 May 2015].

Conil E, Hadjem A, Lacroux F, Wong MF, Wiart J. 2008. Variability analysis of SAR from $20 \mathrm{MHz}$ to $2.4 \mathrm{GHz}$ for different adult and child models using finite-difference time-domain. Phys Med Biol 53:1511-1525.

EU FP7 Program. 2014. Available from: http://ec.europa.eu/ research/fp7/index_en.cfm [Last accessed 30 March 2015].

Gati A, Hadjem A, Wong MF, Wiart J. 2009. Exposure induced by WCDMA mobiles phones in operating networks. IEEE Trans Wireless Commun 8:5723-5727.

Gati A, Conil E, Wong MF, Wiart J. 2010. Duality between uplink local and downlink whole-body exposures in operating networks. IEEE Trans Electromagn Compatib 52:829-836.

Harmonized European Time Use Surveys (HETUS). 2000. Available from: https://www.h2.scb.se/tus/tus/ [Last accessed 30 March 2015].

ICNIRP. 1998. Guidelines for limiting exposure to time-varying electric, magnetic and electromagnetic fields (up to 300 GHz). Health Phys 74:494-522.

INSEE, (Institut National de la Statistique et des Études Économiques). 2011. INSEE Première $n^{\circ} 1377$, November.

Joseph W, Vermeeren G, Verloock L, Heredia MM, Martens L. 2008. Characterization of personal RF electromagnetic field exposure and actual absorption for the general public. Health Phys 95:317-330.

Lauer O, Frei P, Gosselin MC, Joseph W, Röösli M, Fröhlich J. 2013. Combining near- and far-field exposure for an organspecific and whole-body RF-EMF proxy for epidemiological research: A reference case. Bioelectromagnetics 34:366-374.

Mohler E, Frei P, Aydin A, Buergi A, Röösli M. 2009. Personal exposure to high-frequency electromagnetic fields in the region of Basel (Switzerland): An overview of the Qualifex study. Umweltmed Forsch Prax 14:329-338. 
Nagaoka T, Watanabe S. 2008. Postured voxel-based human models for electromagnetic dosimetry. Phys Med Biol 53:7047-7061.

Plets D, Joseph W, Vanhecke K, Tanghe E, Martens L. 2012. Coverage prediction and optimization algorithms for indoor environments. EURASIP 2012:123.

Plets D, Joseph W, Aerts S, Vanhecke K, Martens L. 2014. Prediction and comparison of downlink electric-field and uplink localized SAR values for realistic indoor wireless planning. Radiat Prot Dosim 162:487-498.

Sadetzki S, Eastman Langer C, Bruchim R, Kundi M, Merletti F, Vermeulen R, Kromhout $H$, Lee AK, Maslanyj $M$, Sim MR, Taki M, Wiart J, Armstrong B, Milne E, Benke G, Schattner R, Hutter HP, Woehrer A, Krewski D, Mohipp C, Momoli F, Ritvo P, Spinelli J, Lacour B, Delmas D, Remen T, Radon K, Weinmann T, Klostermann S, Heinrich S, Petridou E, Bouka E, Panagopoulou P, Dikshit R, Nagrani R, Even-Nir H, Chetrit A, Maule M, Migliore E, Filippini G, Miligi L, Mattioli S, Yamaguchi N, Kojimahara N, Ha M, Choi KH, Mannetje A, Eng A, Woodward A, Carretero G, Alguacil J, Aragones N, SuareVarela MM, Goedhart G, Schouten-van Meeteren AA, Reedijk AA, Cardis E. 2014. The MOBI-Kids study protocol: Challenges in assessing childhood and adolescent exposure to electromagnetic fields from wireless telecommunication technologies and possible association with brain tumor risk. Frontiers in Public Health ePub 10. 3389.

Schüz J, Elliott $\mathrm{P}$, Auvinen A, Kromhout H, Poulsen AH, Johansen C, Olsen JH, Hillert L, Feychting M, Fremling K, Toledano $M$, Heinävaara $S$, Slottje $P$, Vermeulen R, Ahlbom A. 2011. An international prospective cohort study of mobile phone users and health (Cosmos): Design considerations and enrolment. Cancer Epidemiol 35:37-43.

Taflove A, Hagness SC. 2000. Computational electrodynamics: The finite-difference time-domain method, 2nd ed. Boston, MA: Artech House Publishers. p 1006.

Tesanovic M, Conil E, De Dominico A, Aguero R, Freudenstein F, Correia LM, Bories S, Martens L, Wiedemann PM, Wiart J. 2014. Wireless networks and EMF - paving the way for low-EMF networks of the future: The LEXNET project. IEEE VTC Magazine 9:20-28.

TNS (Taylor Nelson Sofres) survey. 2010. Mobile et société. Journal of Expertise of the French Association of Mobile Operators (AFOM) $\mathrm{n}^{\circ} 12$.

Wiart J, Hadjem A, Wong MF, Bloch. I. 2008. Analysis of RF exposure in the head tissues of children and adults. Phys Med Biol 53:3681-3695. 